\title{
PROPRIEDADES QUÍMICAS E FÍSICAS DE SOLOS EM ÁREAS SOB PASTAGENS EM CERRADO DO NORTE DO TOCANTINS
}

\author{
Chemical and physical properties of soil in areas under pastures in \\ cerrado vegetation in Tocantins State, Brazil
}

\author{
Antonio Clementino dos Santos ${ }^{a}, E^{2}$ vandro Maia Ferreira ${ }^{b}$, Leandro Coelho de Araújo ${ }^{c}$ \\ a Engenheiro A grônomo, Professor adjunto III do curso deZ ootecnia, Programa de Pós-G raduação em CiênciaAnimal Tropical \\ ePrograma de Pós-G raduação em Produção Vegetal, Bolsista de ProdutividadeCNPq, Câmpus Universitário de Araguaína/ \\ UFT, Araguaína, TO - Brasil, e-mail: clementino@ uft.edu.br \\ b ZootecnistaBolsistaPIBIC/ CNPq-UFT, Mestreem Agronomia,ESALQ / USP, Piracicaba, SP - Brasil, e-mail:zoomaia@ hotmail.com \\ c ZootecnistaBolsistaPIBIC/ CNPq-UFT, Mestreem Agronomia, ESALQ/ USP,Piracicaba, SP - Brasil,e-mail:leandropara@ hotmail.com
}

\begin{abstract}
Resumo
A condição de densidade e tipo de solo tem importância para orientar o manejo de pastagem em uma área. $O$ presente trabalho realizado no município de Wanderlândia, Estado do Tocantins, teve por objetivo caracterizar ambiente de pastagem, dando ênfase às classes de solos, com a finalidade de mensurar e avaliar a degradação de pastagens. Essas áreas situam-se em domínio de Latossolo Vermelho distrófico e N eossolo Q uartzarênico órtico cultivadas por pastagem ("Brachiaria brizantha" [Hochst.] Stapf). Verificou-se pelos resultados que as mudanças de classes de solos levaram as alterações no pH, densidade do solo e, em consequência, redução na quantidade total de poros, principalmente nas primeiras camadas do horizonte A. As amostragens realizadas foram eficientes, uma vez que proporcionaram subsídios para a avaliação do nível de degradação, revelando que o manejo inadequado do solo compromete o desenvolvimento da pastagem (número de perfilhos e touceiras). Concluindo, os resultados mostraram maior estande de planta nas áreas com N eossolo Q uartzarênico órtico quando comparadas com Latossolo, revelando que o manejo adotado neste último solo está sendo subutilizado.
\end{abstract}

Palavras-chave: Conservação de pastagem. Manejo de pastagem. Relação solo/ planta/ animal. 


\begin{abstract}
The bulk density and soil classes are important for providing directions for pasture management. The current research was carried out in the municipality of Wanderlândia, northern area of State of Tocantins. The objective of this study was to characterize the environment of pasture, emphasizing the soils classes in order to measure and evaluate the pasture degradation. These areas are basically formed by Ultisol and Entisol pasture cultivated using "Brachiaria brizantha" (Hochst) Stapf. The obtained data showed that different soil classes, determined changes in $p H$, bulk density and consequently reduction in total soil porosity mainly in first layers of " $A$ " horizon. The samples collected were considered efficient once they provided subsidies to evaluate the degradation rate, showing that inadequate soil management have direct influence in developing of pasture. Concluding, the results showing a large stand of plants found in Entisol areas compared with Ultisol reveals that soil management is under-utilized in the study area.
\end{abstract}

Keywords: Pasture conservation. Pasture management. Soil vs. plant and animal relation.

\title{
INTRODUÇÃO
}

O conhecimento da variabilidade espacial do solo é importante na avaliação da fertilidade para fins de recomendação de adubação, implantação e manejo de pastagens. De acordo com Carvalho et al. (1998), pela própria natureza dos fatores responsáveis pela formação do solo, este apresenta heterogeneidade, tanto vertical como horizontal (REICHARDT, 1985; UPCHURCH; ED MOND S, 1991).

A maioria das pastagens na pecuária de corte está implantada em regiões de cerrado ou em áreas marginais de menor fertilidade, e são exploradas de forma extrativista. 0 mau estabelecimento, espécie forrageira não adaptada, manejo inadequado, redução na fertilidade do solo, são considerados os principais responsáveis pela degradação das pastagens. A sazonalidade da produção forrageira acarreta ainda baixa capacidade de suporte no período de estiagem, dificultando o manejo animal $\mathrm{x}$ planta, exigindo suplementação alimentar e/ ou variação da carga animal, que, quando mal realizadas, acarretam baixos índices zootécnicos.

A degradação de pastagens é processo evolutivo de perda de vigor, de produtividade e de capacidade de recuperação natural, que a torna incapaz de sustentar os níveis de produção e de qualidade exigidos pelos animais, bem como de superar os efeitos nocivos de pragas, doenças e invasoras (MACED 0, 1995).

As pastagens representam forma racional de conservação das características e propriedades físicas do solo, desde que bem manejadas, com reposição de nutrientes e lotação adequada. Todavia, o que se observa com frequência é a adoção das práticas de manejo, que culminam com a degradação do solo. Conforme estimativas de Macedo e Zimmer (1993), 80\% das pastagens cultivadas no bioma Cerrado estão degradadas ou em processo de degradação.

Independente da co bertura vegetal em determinada área tem-se que conhecer e compreender a composição e a dinâmica dos processos internos do solo, pois, afinal, a relação solo - planta - animal depende das propriedades químicas, físicas e biológicas do solo. Muito mais do que suporte físico para as plantas, o solo é o meio onde ocorrem reações e processos determinantes do sucesso ou insucesso da recuperação ou estabelecimento de pastagens. 
É necessário definir atributos de solo e do ambiente sensíveis ao manejo e de fácil determinação, que permitam acompanhar as mudanças na qualidade do solo. Esta informação poderá então ser utilizada para sugerir modificações nos sistemas de manejo em uso pelos produtores, a tempo de evitar a degradação do solo pela erosão e queda da fertilidade (MIELNICZUK, 1999).

A classificação e o estudo das propriedades do solo podem determinar o potencial das terras de forma que se utilize adequadamente (manejo, capacidade de uso, forrageira adequada etc.), sem causar danos consideráveis. Além do citado anteriormente deve-se levar em conta o clima, a intensidade de uso, os impedimentos à moto-mecanização e as condições de infraestrutura (LEPSCH, 1991).

A caracterização das propriedades químicas, físicas e classificação do solo em área sob pastagem é a base fundamental para delineamento do manejo sustentável da terra em áreas com características semelhantes. $\mathrm{O}$ conhecimento da heterogeneidade dos solos também é importante para desenvolver esquemas de amostragem de solo e definir práticas de manejo.

A análise espacial demonstra sua viabilidade para este tipo de estudo, permitindo fazer 0 mapeamento da área de acordo com o tipo e propriedade de solo mais semelhante; isso conduz a uma pecuária de precisão, auxiliando aos pecuaristas nas tomadas de decisões. A busca da sustentabilidade socioeconômica da exploração agropecuária ou a procura de nova condição de equilíbrio do sistema de produção passa pelo manejo adequado do solo e das pastagens (FREG ONEZI et al., 2001).

D entre os vários sistemas de usos da terra existentes, as maiores alterações nas características químicas do solo ocorrem sob exploração extensiva das pastagens, com capital e nível tecnológico mínimo. A pecuária extensiva requer baixo nível de consumo de insumos externos à propriedade e, consequentemente, depende pouco do aporte de energia externa, buscando adaptar-se o máximo possível ao meio ambiente, de forma que, quanto mais heterogêneo for o meio, mais diversificado será o sistema no tempo e no espaço (ALVARENG A; DAVIDE, 1999).

A produtividade de espécies forrageiras de área é influenciada pela fertilidade dos solos. Estes podem ser naturalmente férteis ou se tornarem férteis através do manejo adequado. Para tal, é necessário se conhecer e quantificar a variação das suas propriedades químicas, uma vez que eles, por serem sistemas dinâmicos e abertos, estão em constantes modificações, constituindo assim corpos heterogêneos (SILVA; CHAVES, 2001).

O estudo da variabilidade das propriedades dos solos é particularmente importante em áreas onde o solo está submetido a diferentes manejos, pois a análise pode indicar alternativas de manejo não só para reduzir os efeitos da variabilidade do solo na produção das culturas, mas também para aumentar a possibilidade de se estimarem respostas dos atributos do solo em função de determinadas práticas de manejo. Com base no exposto, o presente trabalho teve como objetivo avaliar as características físicas dos solos nos diferentes piquetes na área em estudo e a influência desses fatores na cobertura do solo e no desenvolvimento radicular das pastagens.

\section{MATERIAIS E MÉTODOS}

A área em estudo localiza-se no município de Wanderlândia, na Fazenda Cerambo, Estado do Tocantins (Figura 1), que fica entre o divisor da Bacia Hidrográfica do Tocantins com a Bacia Hidrográfica do Araguaia, duas das mais importantes bacias brasileiras. As precipitações pluviométricas locais apresentam médias anuais de $1.500 \mathrm{~mm}$. 0 relevo é caracterizado por áreas planas a suave ondulado, no entanto, encontram-se áreas com relevo ondulado a fortemente ondulado. 


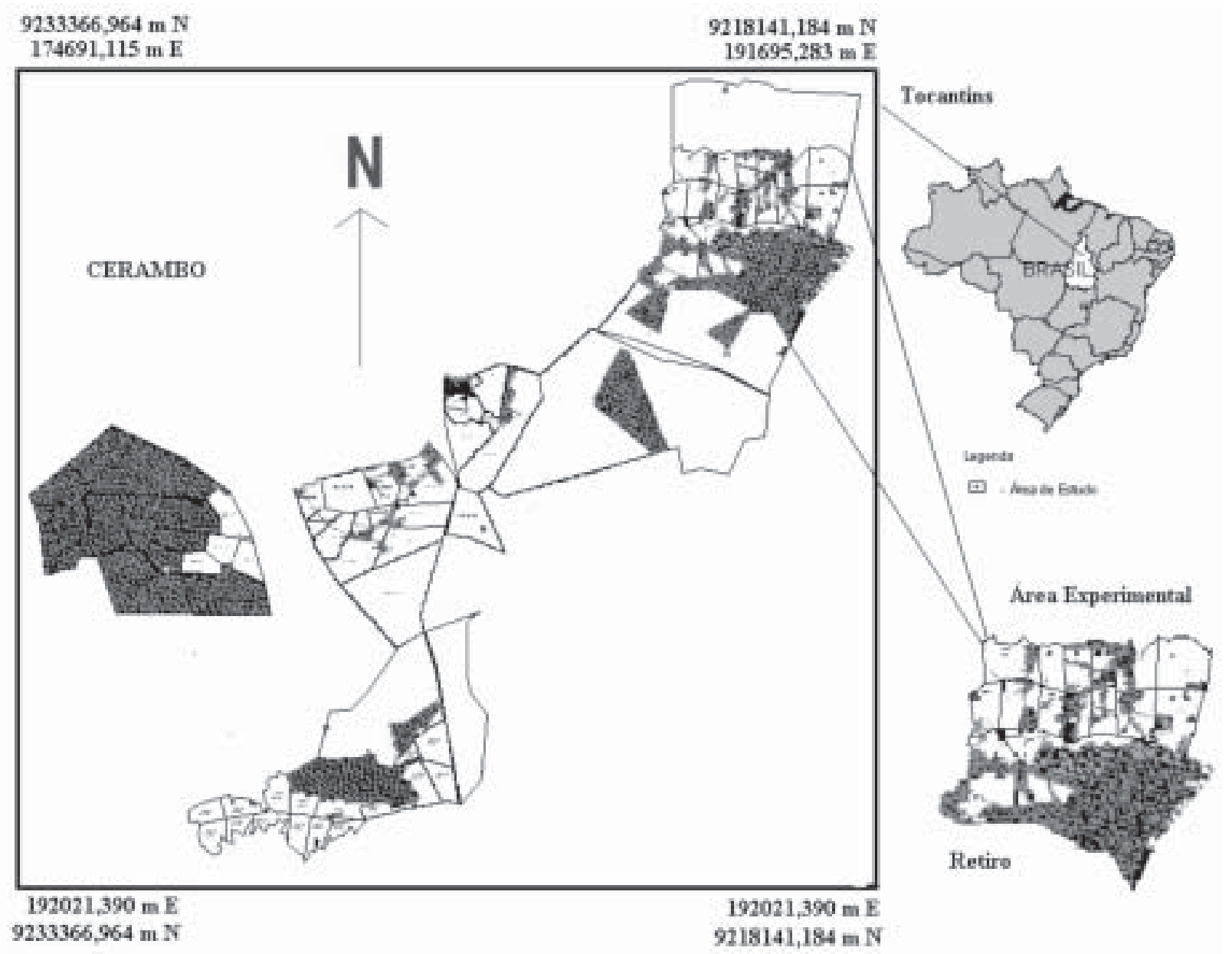

FIG URA 1 - Localização da área experimental

O s perfis foram caracterizados segundo o manual de descrição e coleta de solo no campo (LEMO S; SANTOS, 1996) e classificados de acordo com o Sistema Brasileiro de Classificação de Solos (EMBRAPA, 2006). A pós descrição dos perfis, amostras foram coletadas, deformadas e não deformadas por horizonte ou camadas, visando à caracterização química e física dos solos.

Além das amostras coletadas nas trincheiras, como a área experimental é dividida em piquetes, coletou-se ainda doze amostras (oito deformadas e quatro não deformadas) por piquetes, sendo que as amostras deformadas foram divididas em duas profundidades: 4 amostras de 0-10 $\mathrm{cm}$ e 4 amostras de 10-20 cm. As amostras deformadas foram pré-tratadas: secas ao ar, destorroadas e passadas em peneira de $2 \mathrm{~mm}$, para a obtenção da terra fina seca ao ar e determinada em laboratório as seguintes análises: granulometria, densidade, porosidade total e pH do solo (EMBRAPA, 1997), enquanto que as amostras não deformadas foram colocadas em estufa a $105^{\circ} \mathrm{C}$ pelo período de 24 horas, em seguida, colocadas em dissecadores por 0,5 horas e, posteriormente, pesadas para determinação da densidade do solo pelo método do cilindro constante (FORSYTHE, 1975).

As amostras de solo descritas acima foram georeferenciadas com auxílio de técnicas de localização por sistema de posicionamento global (GPS).

Para avaliar a degradação da pastagem existente na área experimental, touceiras e perfilhos foram quantificados de modo casualizado, utilizando-se um quadrado de $0,25 \mathrm{~m}^{2}$, obtendo-se um total de quatro repetições por piquete. O bservou-se ainda o desenvolvimento radicular ao longo do perfil do solo.

Para a descrição dos resultados realizou-se uma análise exploratória dos dados (média, desvio-padrão, etc.). 


\section{RESULTADOS E DISCUSSÃO}

$\mathrm{Na}$ Tabela 1 encontram-se os resultados das propriedades físicas e pH para as classes de solos presentes na área experimental, as quais possuem características e/ ou propriedades diferenciadas, podendo ser fator para entender de forma espacial a variabilidade e compreender a diferenciação na produtividade. Através dessa classificação, foram observados na área diferentes tipos de solos, dentre eles destacou-se o Neossolo Litólico, Neossolo Q uartzarênico órtico, Plintossolo e Latossolo Vermelho eutroférrico e Latossolo Vermelho.

TABELA 1 - Propriedades físicas e pH de solos em seus respectivos horizontes

\begin{tabular}{|c|c|c|c|c|c|c|c|}
\hline Perfil & Latitude & Longitude & Camadas & $\begin{array}{l}\text { Profundidade } \\
\text { (cm) }\end{array}$ & $\begin{array}{l}\mathrm{pH} \\
\mathrm{KCl}\end{array}$ & $\begin{array}{l}\text { ds } \\
\left(\mathrm{g} \mathrm{cm}^{-3}\right)\end{array}$ & $\begin{array}{l}\text { PT } \\
(\%)\end{array}$ \\
\hline \multirow[t]{6}{*}{ P1 } & 0190487 & 9231170 & Ap & $0-10$ & 5,3 & 1,42 & 45,29 \\
\hline & & & $\mathrm{Ba}$ & $10-18$ & 4,33 & 1,53 & 41,34 \\
\hline & & & B & $18-38$ & 4,5 & 1,29 & 50,42 \\
\hline & & & $\mathrm{BC}$ & $38-70$ & 3,12 & 1,47 & 43,32 \\
\hline & & & $\mathrm{Cb}$ & $70-93$ & 2,83 & 1,44 & 44,74 \\
\hline & & & C & $93+$ & 2,63 & 1,45 & 44,26 \\
\hline \multirow[t]{4}{*}{ P2 } & 188075 & 9231328 & Ap & $0-20$ & 3,95 & 1,42 & 45,31 \\
\hline & & & $\mathrm{Ab}$ & $20-32$ & 3,75 & 1,46 & 43,83 \\
\hline & & & $\mathrm{Ba}$ & $32-47$ & 3,57 & 1,31 & 49,46 \\
\hline & & & B & $47-100+$ & 3,4 & 1,32 & 49,12 \\
\hline \multirow[t]{6}{*}{ P3 } & 187857 & 9230658 & Ap & $0-18$ & 3,23 & 1,37 & 47,49 \\
\hline & & & A1 & $18-37$ & 2,87 & 1,35 & 48,09 \\
\hline & & & $\mathrm{Ab}$ & $37-44$ & 3,49 & 1,26 & 51,60 \\
\hline & & & $\mathrm{Ba}$ & $44-52$ & 3,5 & 1,26 & 51,60 \\
\hline & & & B1 & $52-79$ & 2,93 & 1,28 & 50,90 \\
\hline & & & B2 & $79-85+$ & 3,08 & $* * *$ & $* * *$ \\
\hline \multirow[t]{2}{*}{ P4 } & 0187749 & 9230218 & Ap & $0-10$ & 3,02 & 1,28 & 50,86 \\
\hline & & & $\mathrm{C}$ & $10-30$ & & & \\
\hline \multirow{3}{*}{ P5 } & 0187818 & 9229438 & Ap & $0-27$ & 3,77 & 1,70 & 34,72 \\
\hline & & & $\mathrm{A} 1$ & $27-57$ & 3,81 & 1,72 & 33,67 \\
\hline & & & A2 & $57-97+$ & 2,97 & 1,65 & 36,44 \\
\hline
\end{tabular}

P1:Plintossolo; P2: Latossolo Vermelho eutroférrico; P3: Latossolo Vermelho; P4: Neossolo Litólico; P5: Neossolo Quartizarênico órtico; *** Pastagem natural de H iparrhenia rufa.

Os Latossolos encontrados na área em estudo foram o Latossolo Vermelho eutroférrico e Latossolo Vermelho; esses solos naturalmente apresentam boas propriedades físicas. São profundos, porosos, permeáveis, friáveis, bem estruturados e de fácil preparo, tendo, portanto, alto potencial para a agropecuária. No entanto, observando a Tabela 1, nota-se que as camadas correspondentes ao horizonte $\mathrm{Ab}$ e A apresentam uma densidade de 1,46 e 1,35 g. $\mathrm{cm}^{-3}$ para o Latossolo Vermelho eutroférrico e Latossolo Vermelho, respectivamente, quando o ideal para esses solos de textura Argilo-arenosa (ArgAr) e Muito-argilosa (MArg) seria cerca de 1 g. $\mathrm{cm}^{-3}$, o que demonstra a existência de uma camada compactada. O bserva-se ainda valores de $\mathrm{pH}$ mais baixos para as camadas inferiores ao horizonte Ap, em relação aos outros horizontes em ambos os solos. A presença de camadas compactadas a partir dos dez centímetros em Latossolos ocupados com pastagens mal manejadas é comum, uma vez que o impacto direto das patas dos animais sobre o solo com cobertura vegetal escassa e sem descanso adequado, após o período seco para expansão de seu sistema radicular, se reflete a partir dessa profundidade. 
Com base nas observações de campo, nota-se que $90 \%$ dos sistemas radiculares das pastagens encontram-se nos primeiros $10 \mathrm{~cm}$ do solo e apresentam crescimento horizontal (Figura 2). D essa forma, fica evidente a presença de camada compactada (barreira física) associada ao baixo $\mathrm{pH}$ (barreira química) vindo a restringir o desenvolvimento vertical do sistema radicular, além de favorecer a menor infiltração de água no solo, ocasionando processos erosivos que contribuem para a redução da fertilidade do solo.

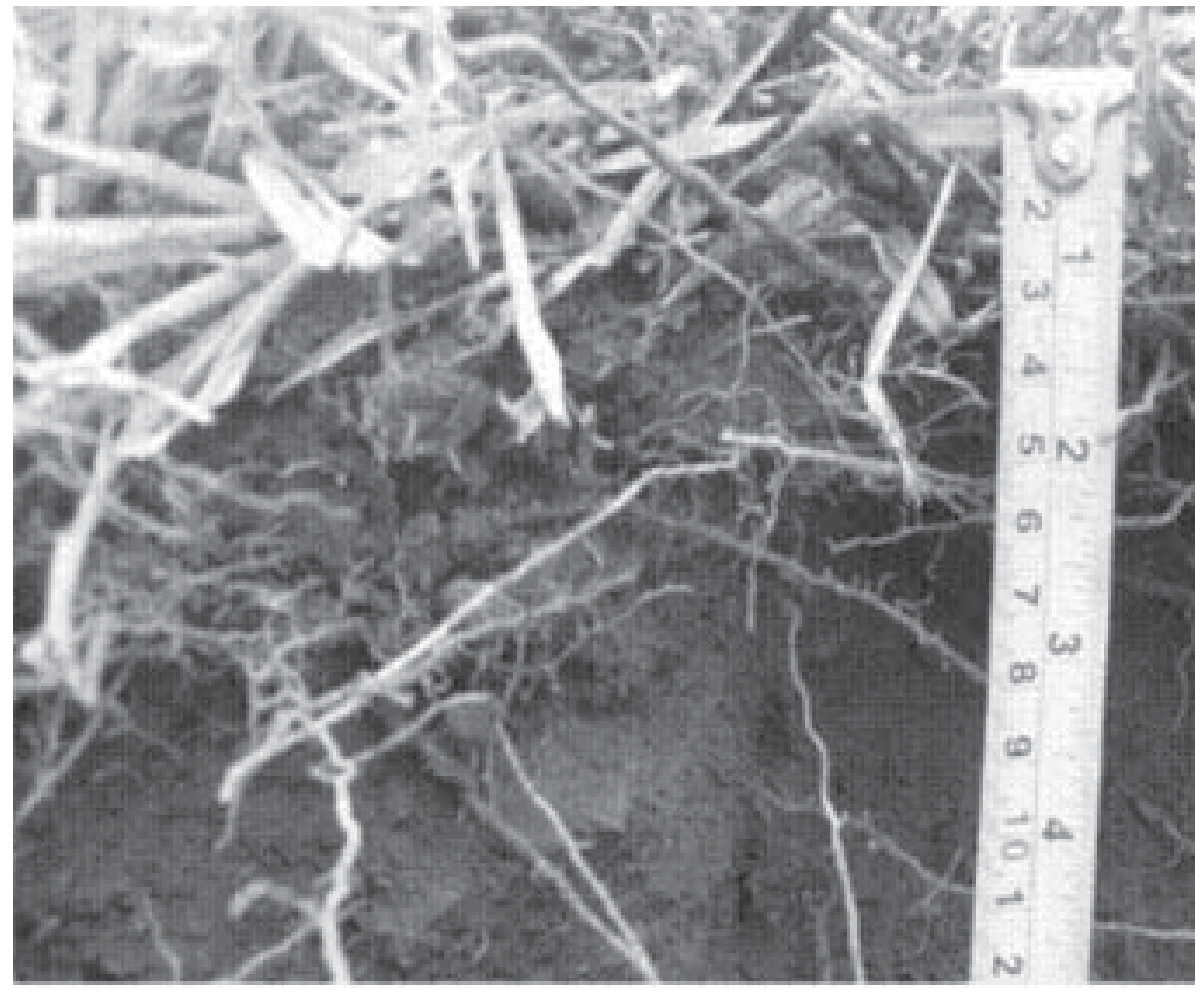

FIGURA 2 - Desenvolvimento superficial do sistema radicular

Ao mesmo tempo, a presença das "barreiras" químicas e físicas faz com que a planta forrageira explore menor volume de solo, absorvendo, portanto, menos nutrientes e ficando mais susceptíveis a déficits hídricos no período seco do ano; esses fatores associados culminam em menor cobertura vegetal e degradação das pastagens.

Para se obter boa produtividade nestes solos é necessário o preparo adequado, escolha de forrageiras adaptadas e aplicação de corretivos, pois a acidez tem contribuído para que o solo não expresse 0 seu real potencial produtivo e, consequentemente, o não estabelecimento adequado das pastagens cultivadas, o que evidencia que 0 atual manejo não está sendo adequado.

A pastagem artificial de "Brachiaria brizantha" implantada no Neossolo Litólico não conseguiu se manter (Tabela 2), permanecendo apenas a pastagem natural de "H iparrhenia rufa". Isto se deve à pouca profundidade desse solo, restringindo o desenvolvimento radicular da planta apenas aos primeiros $10 \mathrm{~cm}$ de profundidade. 
TABELA 2 - Físicas e pH do solo em distintos piquetes sob Brachiaria brizantha

\begin{tabular}{llllllll}
\hline $\begin{array}{l}\text { Classes } \\
\text { de solos }\end{array}$ & $\begin{array}{l}\text { Classe } \\
\text { Textural }\end{array}$ & $\begin{array}{l}\mathbf{d s} \\
\mathbf{g ~ c m}^{-3}\end{array}$ & $\begin{array}{l}\mathbf{P t} \\
\mathbf{9}\end{array}$ & $\mathbf{p H}$ & $\begin{array}{l}\text { Kpf } \\
\mathbf{u n}\end{array}$ & $\begin{array}{l}\mathbf{n t c} \\
\mathbf{u n}\end{array}$ & $\begin{array}{l}\mathbf{p} / \mathbf{t} \\
\mathbf{u n}\end{array}$ \\
\hline PT & M. Arg & $1,44 \pm 0,10$ & $44,683,75$ & $3,94 \pm 0,14$ & $25,54 \pm 13,10$ & $8,2 \pm 52,22$ & 3,10 \\
LE & ArgAr & $1,49 \pm 0,12$ & $42,49 \pm 4,75$ & $3,78 \pm 0,63$ & $44,91 \pm 13,43$ & $13,49 \pm 2,99$ & 3,33 \\
LR & M. Arg & $1,41 \pm 0,03$ & $45,72 \pm 0,96$ & $3,7 \pm 40,74$ & $54,45 \pm 13,28$ & $14,98 \pm 5,51$ & 3,63 \\
R & M. Arg & $1,2 \pm 0,07$ & $53,75 \pm 2,88$ & $3,45 \pm 0,50$ & $* * *$ & $* * *$ & $* * *$ \\
NQ & Ar & $1,57 \pm 0,09$ & $39,56 \pm 3,58$ & $4,29 \pm 0,46$ & $38,78 \pm 22,49$ & $10,29 \pm 6,65$ & 3,77 \\
\hline
\end{tabular}

PT: Plintossolo; LE: Latossolo Vermelho-Escuro; LR: Latossolo Roxo; R: Neossolo Litólico; NQ: Neossolo Quartzarênico; ds: densidade do solo; pt: porosidade total; npf: número de perfilhos; $\mathbf{n t c :}$ número de touceira; $\mathbf{n p f} / \mathbf{n t c}$ : relação entre 0 número de perfilho e touceiras; $* * *$ Pastagem natural.

A relação entre o número de perfilhos e touceiras nas diferentes classes de solos é apresentada na Figura 3, notando-se que o Plintossolo apresenta a menor relação, certamente pelos motivos já comentados no parágrafo anterior.

O Neossolo Q uartzarênico órtico apresenta a maior relação, porém todas as relações são inferiores a quatro perfilhos por touceira (Figura 3), evidenciando o pouco perfilhamento da forrageira em todas as classes de solo estudadas, o que se reflete em uma pastagem com baixa produção de matéria seca ha-1, por conseguinte, baixa capacidade de suporte.

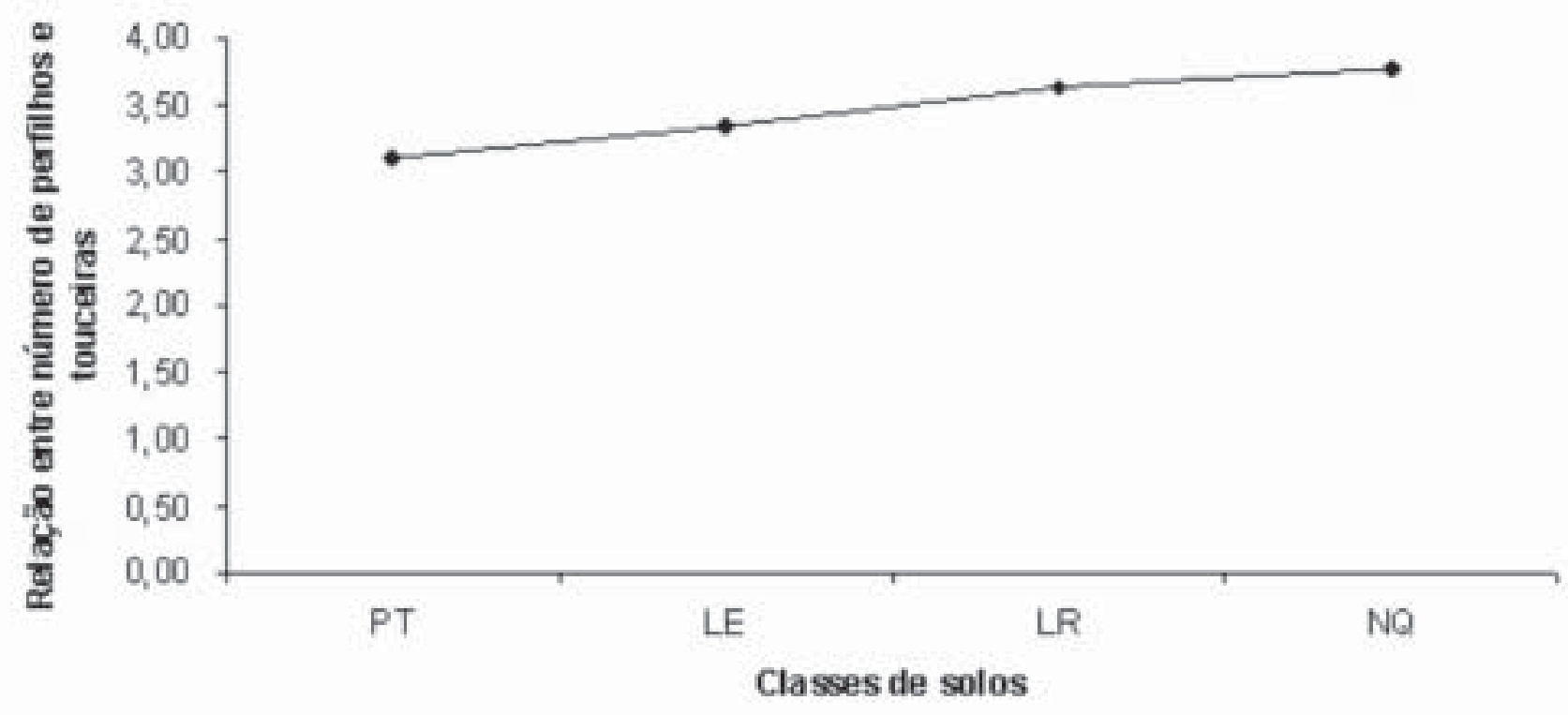

FIGURA 3 - Relação entre o número deperfilhos e touceiras, eas classes de solos. PT: Plintossolo; LE: Latossolo Vermelho eutroférico; LR: Latossolo Vermelho; R: Neossolo Litólico; NQ: Neossolo Quartizarênico órtico 
Na Figura 4 é apresentada a produção de perfilhos e touceiras da Brachiaria brizantha em função das classes de solos; com base nos resultados, não foram constatadas diferenças estatísticas significativas $(p>0,05)$ no número de perfilhos e touceiras entre as classes de solos, Latossolo Vermelho, Latossolo Vermelho eutroférrico e Neossolo Quartzarênico órtico, mostrando que os solos com maiores teores de argila, textura (MArg e ArgAr) Latossolo Roxo, Latossolo V ermelho eutroférrico, sequencialmente (Tabela 2), apesar de serem potencialmente mais produtivas que o Neossolo Q uartzarênico órtico, textura (Ar); quando apresentam acidez elevada $(\mathrm{pH}<4,0)$ (Tabela 1) não expressam seu potencial produtivo, pois, nessas condições, a maior parte dos nutrientes encontra-se precipitada e, consequentemente, indisponíveis para absorção, ocorrendo nestas condições menor desenvolvimento da planta forrageira (Brachiara brizantha). Havendo, no entanto, significância para número de perfilhos entre o Plintosso e o Latossolo Vermelho (Figura 4), tal diferença certamente se deve à maior densidade do horizonte Ba na camada de $(10-18 \mathrm{~cm})$ do Plintossolo (Tabela 1), caracterizada por uma barreira física que limita o desenvolvimento radicular e, consequentemente, o perfilhamento da planta forrageira.

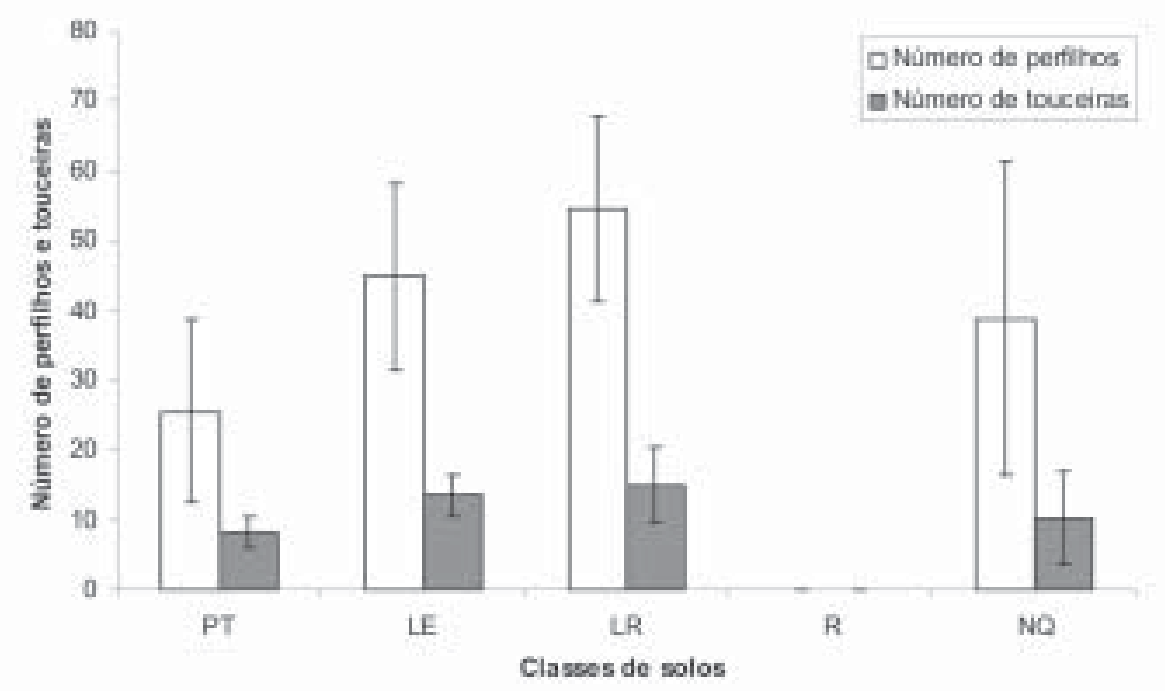

FIGURA 4 - Relação entre as classes de solos e o número de perfilhos e touceiras. PT: Plintossolo; LE: Latossolo Vermelho eutroférrico; LR: Latossolo Vermelho; R: Neossolo Litólico; NQ: Neossolo Quartzarênico órtico

\section{CONCLUSÕES}

A área estudada é heterogenia quanto às classes de solos apresentadas: Neossolo litólico, Neossolo Quartzarênico órtico, Plintossolo, Latossolo Vermelho eutroférrico e Latossolo Vermelho.

Cada tipo de solo apresenta propriedades químicas e físicas $(\mathrm{pH}$, densidade, porosidade, etc.) particulares. No entanto, todos eles apresentam compactação e acidez elevada (pH menor que quatro). A acidez do solo associada à presença de uma camada compactada a partir dos $10 \mathrm{~cm}$ tem limitado o desenvolvimento do sistema radicular das plantas forrageiras.

As plantas forrageiras apresentaram baixa relação entre o número de perfilhos e touceira, 0 que demonstra o baixo perfilhamento e desenvolvimento deles, como reflexo do manejo e das propriedades físicas e químicas limitantes ao desenvolvimento da pastagem.

\section{AGRADECIMENTOS}

Os autores agradecem ao CNPq pelas bolsas concedidas, ao SEPLAN/ CNPq e UFT pelo apoio financeiro, como também ao proprietário da Fazenda Cerambo por permitir o acesso à propriedade e apoio, o que tornou este trabalho possível. 


\section{REFERÊNCIAS}

ALVARENGA, M. I. N.; DAVIDE, A. C. Características físicas e químicas de um latossolo Vermelho-escuro e a sustentabilidade de agroecossistemas. Rev. Bras. Cienc. Solo, Viçosa, n. 23, p. 933-942, 1999.

CARVALHO, O. S. et al. Variabilidade espacial de algumas propriedades químicas e físicas de um solo submetido a diferentes sucessões de cultivo. Rev. Bras. Cienc. Solo, Viçosa, v. 22, n. 3, p. 497-503, 1998.

EMPRESA BRASILEIRA DE PESQUISA AGRO PECUÁRIA - EMBRAPA. Centro Nacional de Pesquisa de Solos. Manual de métodos de análise de solos. 2. ed. Rio de Janeiro: Embrapa Solos, 1997.

. Centro Nacional de Pesquisa de Solos. Sistema brasileiro de classificação de solos. 2. $\bar{e} \bar{d} . \bar{R} \bar{i}$ de Janeiro: Embrapa Solos, 2006.

FORSYTHE, W. M. Física de suelos: manual de laboratório. Costa Rica: Instituto Interamericano de Ciências Agrícolas, 1975.

FREGONEZI, G. A. F. et al. Modificações morfológicas e físicas de um Latossolo argiloso sob pastagens. Rev. Bras. Cienc. Solo, Viçosa, v. 25, n. 4, p. 1017-1027, 2001.

LEMO S R. C.; SANTOS, R. D. Manual de descrição e coleta de solo no campo. 2. ed. Campinas: Sociedade Brasileira de Ciência do Solo, 1996.

LEPSCH, I. F. Manual para levantamento utilitário do meio físico e classificação de terras no sistema de capacidade de uso. 4. ed. Campinas: Sociedade Brasileira de Ciência do Solo, 1991.

MACED O, M. C. M. Pastagem nos ecossistemas cerrados: pesquisas para o desenvolvimento sustentável. In: SIMPÓ SIO SOBRE PASTAGENS NOS ECOSSISTEMAS BRASILEIROS, 1., 1995. Brasília. Anais... Brasília, Sociedade Brasileira de Zootecnia, 1995. p. 28-62.

MACED O, M. C. M.; ZIMMER, A. H. Sistema pasto - lavoura e seus efeitos na produtividade agropecuária. In: SIMPÓ SIO SOBRE ECO SSISTEMAS DE PASTAGENS, 2., Jaboticabal. 1993. Anais... Jaboticabal: FUNEP, 1993. p. 216-245.

MIELNICZUK, J. Matéria orgânica e a sustentabilidade de sistemas agrícolas. In: SANTO S, G. A.; CAMARG O, F. A. O. (Ed.). Fundamentos da matéria orgânica do solo: ecossistemas tropicais e subtropicais. Porto Alegre: Genesis, 1999. p. 1-8.

REICHARDT, K. Processos de transferência no sistema solo-planta-atmosfera. Campinas: Fundação Cargil, 1985.

SILVA, P. C. M.; CHAVES, L. H. G. Avaliação e variabilidade espacial de fósforo, potássio e matéria orgânica em Alissolos. Rev. Bras. Eng. Agr. e Amb., Campina Grande, v. 3, n. 5, p. 431-436, 2001.

UPCHURCH, D. R.; ED MOND S, W. J. Statistical procedures for specific objectives. Spatial of soils and landforms. Soil Sci. Soc. of America J., Pittsburgh, n. 28, p. 49-71, 1991. Special publication.

Recebido: $10 / 10 / 2008$ Received: $10 / 10 / 2008$

Aprovado: 02/ 12/ 2008 A pproved: $12 / 02 / 2008$

Revisado: 18/ 08/ 2009 Reviewed: 08/ 18/ 2009 